\title{
LOS USOS Y COSTUMBRES EN TLAXCALA: UN IR Y VENIR HISTÓRICO
}

\author{
Usos y Costumbres in Tlaxcala: a historical sway
}

\author{
Gabriela Georgina MATEOS GÓMEZ
}

\begin{abstract}
Sumario:
Introducción I. Desarrollo histórico de los precedentes de los Usos y Costumbres en Tlaxcala 1.1 Estructura política y social precolonial 1.2. Continuación de la estructura política y la alianza 1.3 El camino hacia la soberanía política 1.4 Los referentes indígenas siguen presentes II. La evolución jurídica de los Usos y Costumbres en Tlaxcala. 2.1 El Sistema de Cargos como raíz de los Usos y Costumbres 2.2 Los Usos y Costumbres: una práctica ancestral en Tlaxcala 2.3 Los Usos y Costumbres bajo la lupa constitucional Conclusiones Fuentes de información
\end{abstract}

Resumen. Tlaxcala, previo al México colonial, estaba estructurada en cuatro señoríos que gozaban de autoridad en sus comunas y que se reunían para discutir lo relativo a todos ellos. Con la alianza que se hizo con España, Cortés les ofreció participar en la dominación de Tenochtitlán, respetar su autonomía, formas de gobierno y adoptar la religión católica. Por ello, en Tlaxcala la organización municipal se conforma en un sistema jurídico que contiene dos sistemas electorales: uno constitucional y otro consuetudinario -Usos y Costumbres-, legitimado 1995.

Palabras clave. Usos y costumbres, sistemas de cargo, democracia, sistemas jerárquicos, cosmovisión

Summary. Tlaxcala, before Mexico's colony, was structured in four lordships that enjoyed authority over their communities and that gathered to discuss everything related to them. With the alliance made with Spain, Cortés offered them to participate in Tenochtitlans domination, respect their autonomy, forms of government and to adopt the catholic religion. Because of that, Tlaxcala's municipal organization is stablished in a legal system that has two electoral systems: One is constitutional and the other is customary-Usos y Costumbres- which was legitimated in 1995.

keywords. Usos y costumbres, charging system, democracy, hierarchical system, worldview

\section{Introducción}

Las características sociales, políticas, económicas y culturales del estado de Tlaxcala se manifiestan entre el pasado y el presente. Se trata de una imbricación entre los remanentes de una

\footnotetext{
* Catedrática de la Licenciatura en Derecho y miembro de la Academia de Metodología en la Universidad Autónoma de Tlaxcala, evaluadora de ANUIES región centro-sur.
} 
organización tradicional y los albores de lo postmoderno: no se ha dejado del todo lo ancestral y tampoco se ha entrado de lleno a lo contemporáneo.

Esto se puede apreciar no solo en la infraestructura, la cultura, la organización del espacio o los modos de producción, sino en la organización social y política al interior de las comunidades. García Canclini lo identifica como hibridación, dado el carácter amplio que considera del término, frente a otros como mestizaje o sincretismo ${ }^{1}$.

Dentro de este carácter amplio, se puede hablar de los Usos y Costumbres. Deben entenderse como el reconocimiento grupal de una forma de proceder, de decir o de pensar, que perdura a lo largo del tiempo y se inscribe en un determinado contexto en el cual se hace evidente la existencia de la costumbre. Hablar de este tema implica hacerlo de procesos o conductas que, al ser repetidas a lo largo del tiempo, adquieren significado y reconocimiento a nivel social.

La organización política y social —al interior de las comunidades del estado de Tlaxcalatiene dos características. La primera es la existencia de un Presidente de Comunidad, cuya denominación y facultades se han modificado desde su aparición en la Ley Orgánica Municipal de 1955 y han llegado a considerase como un cuarto nivel de gobierno. La segunda es la forma en que se elige: a partir de 1998 puede ser mediante el voto libre, secreto y directo. A dicha forma se le conoce como voto constitucional o mediante la elección por Usos y Costumbres.

Así, la organización municipal, se conforma en un sistema jurídico que contiene dos sistemas electorales: uno constitucional y otro consuetudinario. Esta forma consuetudinaria de elección es vigente en 94 comunidades de las 393 existentes en Tlaxcala y en 24 de los 60 municipios de este estado.

El presente trabajo pretende mostrar cuál ha sido el desarrollo histórico y jurídico de los Usos y Costumbres que han intentado salvar una idea de comunidad que no se fragmenta, sino que más bien pueda vivir en común unión bajo ciertas costumbres sociales y políticas. El texto se compone de dos apartados. El primero llamado El desarrollo histórico de los precedentes de los Usos y Costumbres en Tlaxcala que muestra, bajo un bosquejo histórico, cómo se fue configurando la cosmovisión de lo que después sería un estado. Así, se observan las figuras políticas y religiosas que existían previo a la conquista y su reformulación y componenda a partir del virreinato pasando por los grandes procesos como la independencia, la revolución y la construcción del Estado nacional.

El segundo apartado - La evolución jurídica de los Usos y Costumbres en Tlaxcala- permite señalar cómo se ha desarrollado, a nivel normativo, esta forma de elección. Se muestra el paso de los Sistemas de Cargo a su fragmentación puramente política para, después, llevarla a nivel jurídico y pedir su reconocimiento constitucional. Asimismo, se entabla una discusión sobre cómo operan los Usos y Costumbres bajo una democracia, esencialmente occidental en contraposición con una cosmovisión levemente individualista.

\footnotetext{
1 García Calclini, Nestor (1989), Culturas híbridas, Estrategias para entrar y salir de la modernidad, Grijalbo, México.
} 


\section{Desarrollo histórico de los precedentes de los Usos y Costumbres en Tlaxcala}

\section{Estructura política y social precolonial}

Según Gibson² la historia de Tlaxcala data del período previo al México colonial. Sus primeros asentamientos humanos se conformaron por Olmecas, Xicalancas y Zacatecas. El desarrollo del estado permitió el afianzamiento de siete tribus: Xochimilcas, Chalcas, Tepanecas, Culhuas, Tlahuicas, Chichimecas o Tlaxcaltecas y Mexicas que salieron de Chicomoztoc: lugar de las siete cuevas.

La fundación del primer señorío, fechada entre 1335-1337, se originó cuando Camaxtli —deidad-guía - alentó a los Tlaxcaltecas a llegar a las faldas del volcán Matlalcueye e imponerse a los otomíes, que eran quienes poseían esas tierras (Ramos, Sánchez y Díaz, 2016). Al obtener Tepeticpac el territorio se asignó en relación a la línea familiar.

El señor de Tepeticpac dio a su hermano Teyohualminqui el área que correspondería a Ocotelulco y desde donde se erigiría el segundo señorío. El linaje de estos dos altepétl y una segunda migración de teochichimecas, con beneplácito del señor de Tepeticpac, consolidaron Tizatlán y posteriormente Quiauixtlán ${ }^{3}$.

Así, los cuatro señoríos quedaron establecidos: Ocotelulco en el sur, Tepeticpac en el norte, Tizatlán en el oriente y Quiahuiztlán en el poniente. Funcionaban como una República, no existía una capital porque los cuatro eran parte de un mismo gobierno.

La estructura que se gestó a nivel local, desde antes de la conquista española, tuvo fundamento en una red de relaciones familiares, desde las cuales se generó un sistema jerárquico de autoridad que adquirió matices y que se conservó a lo largo del tiempo. Cabe aclarar que no se trató, señala Muñoz (2013), de detentar un poder totalizador, sino que cada uno gozaba de autoridad en sus comunas, pero lo relativo a los cuatro señoríos se acordaba bajo la presencia de cada uno de ellos. Es decir, aunque cada señorío tenía su propio territorio y gobierno, formaban una alianza en la que cada uno era representado por su tecuhtli. Este era un espacio para discutir y solucionar los problemas comunes.

Según Bustamante ${ }^{4}$ los cargos eran rotativos. Esto cohesionó el aspecto territorial e identitario y dio pasó a la continuidad del tipo de estratificación indígena. No puede olvidarse que existieron otros asentamientos. Sin embargo, eran menores y no gozaban de fuerza política.

Bajo este contexto se dio la conquista encabezada por Hernán Cortés. Cuando pisó las tierras del Altiplano central, pidió permiso a los tlaxcaltecas para cruzar por sus tierras y así arribar a Tenochtitlan.

Tanto Xicohténcatl como su padre, el señor de Tizatlán, se opusieron y cuestionaron la creencia de que los hombres blancos representaban el cumplimiento de la profecía del regreso de

\footnotetext{
${ }^{2}$ Gibson, Charles (1991), Tlaxcala en el Siglo XVI, Fondo de Cultura Económica, México.

3 Ramos Galicia, Yolanda; SÁnchez, Jaime y Díaz de la Mora, Armando (2016), Los Colonizadores Tlaxcaltecas, siglos XVI al XIX, Archivo Histórico del Estado de Tlaxcala y Gobierno del Estado de Tlaxcala, México.

${ }^{4}$ Bustamante López, Carlos (2013), El quebrantamiento de los privilegios, autonomía, guerra y constitución gaditana en Tlaxcala, 1780-1824, Universidad Autónoma de Tlaxcala, Benemérita Universidad Autónoma de Puebla, Educación y Cultura, Asesoría y Promoción, S.C. México
} 
Quetzalcóatl. Este cuestionamiento dio paso a una serie de enfrentamientos armados con los españoles en las que las derrotas a los indígenas estuvieron presentes.

Finalmente, se ofreció la paz en el cerro de Tzompantepec el 7 de septiembre de 1519. Con ello nació una alianza. Cortés les ofreció participar en la dominación de Tenochtitlán y respetar su autonomía y formas de gobierno. A cambio, los tlaxcaltecas adoptarían la religión católica. Con el tiempo harían otro tipo de concesiones de orden cultural.

\section{Continuación de la estructura política y la alianza}

Durante el transcurso del período colonial, los cambios en la organización política fueron resultado del proceso de unificación entre dos culturas: la tlaxcalteca y la española. Martínez y Sempat ${ }^{5}$ aseguran que haber sido los Tlaxcaltecas aliados de los conquistadores les trajo, y aún persisten, una serie de duras críticas. Sin embargo, también los eximió de algunos elementos naturales en una conquista.

El resultado de la alianza marcó el rumbo político de Tlaxcala. Los españoles hicieron una serie de concesiones y privilegios que no tuvieron a bien hacer con otras comunidades. Se habla de exenciones secundarias como el uso de ciertas prendas de vestir, hasta algunas que fueron vitales como el permiso de la instalación de un cabildo de los originarios, que no era otra cosa que mantener activos - políticamente - a los miembros de los cuatro señoríos para el cuidado y defensa del estado.

Se continuó y mantuvo la organización política que existía previa a los acuerdos de paz y la copiaron tanto las instituciones religiosas como las de administración pública por dos razones: era una estructura muy parecida a la española que simplemente se hizo converger con la indígena; la segunda es que, como aliados de los españoles — no conquistados- exigieron que se mantuviera el tipo de estratificación ya fijado. Tlaxcala fue, en todo el territorio conquistado, el único lugar que gozaba de un cabildo indio.

Detentar una forma así de gobierno no sólo fue por expedición y aceptación española. Los pobladores tuvieron que defender y hacer valer ante el gobierno español su autonomía. De esta forma, el cabildo comenzó a hacer labores más ejecutivas: calendarizar los días de reunión, el tipo de asistencia, los temas a discutir, las preeminencias de los asientos durante los cabildos, la igualdad entre las cuatro cabeceras y el reconocimiento de que los tlahtoque fungirían como regidores perpetuos con una gubernatura rotativa: Ocotelulco, Tizatlan, Quiahuiztlan y Tepetícpac. Sin embargo, también se especificó que el cabildo no podía sesionar sin la presencia del gobernador español. Ello implicaba dar paso a una serie de negociaciones, pero no a perder su autonomía ${ }^{6}$.

La uniformidad cultural indígena de los señoríos tlaxcaltecas, por la categoría especial dada a la provincia en tanto pueblo aliado, permitió la continuidad de muchas de las formas de organización indígena sobre todo a nivel local. Sin embargo, se requería, como parte de la alianza, incorporar las instituciones europeas. Estas exigían el establecimiento de una capital desde la

\footnotetext{
5 Martínez Barcacs, Andrea y Sempat Assadourian, Carlos (1991), Tlaxcala una historia compartida siglo XVI, Volumen IX, Consejo Nacional para la Cultura y las Artes, Gobierno del estado de Tlaxcala, México.

6 Ídem. 
cual se gobernaba y dirigía a toda la provincia. Para efectos de lo que se solicitaba se dispuso que fuera lo que actualmente es la ciudad de Tlaxcala.

Siendo así, señalan Martínez y Sempat ${ }^{7}$ (1991), el cabildo se conformó por alcaldes ordinarios y de provincia. Los alcaldes ordinarios pertenecían a los antiguos cuatro altépetl que estaban a cargo de la ciudad de Tlaxcala y los de provincia administraban el territorio externo y no gozaban de tanta fuerza política.

La ubicación de una capital y la conformación de este tipo de cabildo permitió que, poco a poco y casi de forma imperceptible, la relación entre los alcaldes, que se asentaban en la ciudad, y el pueblo se fueran desvinculando. Cada vez se focalizaba más la política hacia el centro. Las comunidades, dependiendo de su lejana o cercanía, participan de ella en mayor o menor medida. Incluso la elección de los alcaldes y otros mandos no se realizaba de los pueblos hacia el centro, sino del centro hacia los pueblos. Esto implicaba que se volvían meros ejecutores de la vida púbica o que, a veces, no se enteraran de las disposiciones emitidas.

La desvinculación era mayor porque los pueblos continuaban teniendo una nobleza interna que interactuaba poco con las políticas que nacían en la capital. Adicionalmente, ellos decidían y designaban a ciertas autoridades locales. Esto dependía del tamaño de la población. Con más de 30 tributarios podrían tener un alcalde y regidores. Los asentamientos menores tenían elecciones periódicas en las que nombraban, típicamente, a un "teniente de gobernador", un fiscal o "alguacil real" de la iglesia, un merino, un escribano y mandones de las cuadrillas de trabajadores $^{8}$.

Eran elegibles los tiachcame - hermanos mayores o mandones del pueblo-quienes gozaban de una edad avanzada y, por ende, de un grado mayúsculo de sabiduría y experiencia, así como del respeto irrestricto de la comunidad.

Es necesario señalar que la cosmovisión indígena no separa lo político de lo religioso. Son elementos que están totalmente relacionados entre sí. De esta forma, lo que con la conquista se integró como parroquias requerían el nombramiento de ciertas autoridades: fiscal mayor, fiscal teniente y mayor.

La amalgamación entre las denominadas autoridades civiles y religiosas, que se establecieron en la Nueva España, se afirmó en 1643. A partir de ese año, los sacerdotes seleccionaron a los fiscales. Tal figura se estableció en un orden máximo de importancia porque era uno de los primeros puestos que le ayudarían a ser cacique y principal.

Este es el principio bajo el cual las autoridades volvían a amalgamar, desde los preceptos indígenas y de la Nueva España, a las autoridades del orden político con el religioso, relacionada también con el arraigo geográfico. Este último era de enorme importancia porque dotaba a la persona de gran prestigio y al gozar con esa virtud bien podría considerarse para estar al frente de cualquier cargo y subir en la rígida escala político-religiosa. Asimismo, era una estructura que se hacía patente en los lazos parentales. Esto se explica porque los pueblos tenían pocos pobladores, de los que podían sobresalir alrededor de cinco familias fundadoras. El parentesco reinante en las estructuras de poder no obedecía a algún tipo de nepotismo sino a la naturaleza de la propia población.

Se puede dar cuenta, entonces, de dos tipos de gobierno. El primero focalizado en la capital con un sistema jerárquico que intentaba representar al resto de los pueblos bajo un orden previo a la conquista, pero con elementos españoles. El segundo se trata de un gobierno también

\footnotetext{
7 Ídem.

${ }^{8}$ Íbidem.p. 450.
}

CIENCIA JuRIDICA. Departamento de Derecho. División de Derecho, Política y Gobierno, Universidad de Guanajuato - Año 7, No. 13, 2018 
jerárquico, que goza de una relación entre el orden político y religioso que les permite ser casi independientes, política y económicamente del primero. Ante esta situación había un peligro: que los pueblos tuvieran la intención de independizarse de la capital.

Para contrarrestar esto, se aseguraba que las comunidades fueran catalogadas como pueblos de por sí. El nombramiento se establecía a partir la antigüedad, de mantener una vida religiosa activa, de contar con al menos 30 tributarios y de ser cabecera de barrios.

La normativa anterior permitió contrarrestar la disgregación de comunidades muy pequeñas y con ello fomentar la adhesión a los pueblos y, también, evitar conflictos, porque ya se tenían experiencias en las que las comunidades disgregadas buscaban ser reconocidas para elegir a sus propias estructuras de gobierno.

Esto explica por qué cuando se empezaron a dar los brotes de insurrección por la lucha independentista y los movimientos armados, Tlaxcala tuvo cierta inclinación por apoyar al gobierno virreinal. Esa fue la razón por la cual las batallas no tuvieron lugar en este suelo. La sensación no era la de tener la necesidad de quitarse un yugo porque, como tal, no existía. Fue el único pueblo no conquistado. De ahí que no tuviera que independizarse.

\section{El camino hacia la soberanía política}

Sin embargo, en 1821 con la entrada de Nicolás Bravo, Tlaxcala fue liberada de los nexos con la corona española. Este sería el principio de la lucha para obtenerla soberanía política. El nuevo régimen consideró la unificación de Puebla y Tlaxcala. Este proyecto no se concretó. Este hecho marcó el inicio de un estado que fue degradado por sus nexos con la Corona. Así, Antonio López de Santa Anna incorporó el estado a lo que conformaba la entonces ciudad de México. Hacia 1846, y con la implantación nuevamente del federalismo, se recobró la categoría de territorio, pero no se otorgó la de estado soberano.

Rendón ${ }^{9}$ señala que después de una serie de negociaciones se demostró, al Congreso de la Unión, que el estado tenía la capacidad de autorregulación económica y social. En 1856 se logró la concesión de estado libre y soberano de la Federación.

A partir de este hecho, parecía que Tlaxcala dejaba atrás la histórica herencia pre y post virreinal. Ya no gozaba del sistema social y político ni de la avenencia del gobierno. Sin embargo, las prácticas cotidianas confirmaban la presencia española a través de las haciendas y los asuntos agrícolas, a la vez que la tradición, en términos políticos, seguía de pie en la práctica y muerta en la letra.

Según Ramírez ${ }^{10}$, la economía y la sociedad de Tlaxcala giraban en torno a lo que se puede denominar economía de hacienda. La concentración de las haciendas se daba en cinco municipios: Cuapiaxtla, Calpulalpan, Huamantla, Nativitas y Tlaxco. Su peso era tan aplastante que opacaba sin problema el resto de las actividades económicas.

Los hacendados se hacían presentes a través de la comercialización del pulque y el manejo de las tiendas de raya en sus dominios, en donde se expedía una importante cantidad de bienes de consumo. Es por ello que en Tlaxcala existía, por un lado, un núcleo poderoso de hacendados y rancheros diseminados por toda la entidad y, por el otro, una vasta población campesina en

\footnotetext{
9 Rendón Garcini, Ricardo (1996), Breve historia de Tlaxcala, Fideicomiso Historia de las Américas, El Colegio de México y Fondo de Cultura Económica, México.

${ }^{10}$ Ramírez Rancancio, Mario (1990), El sistema de haciendas en Tlaxcala, Consejo Nacional para la Cultura y las Artes, México.
} 
calidad de pequeños propietarios y jornaleros. Esta estructura comenzó a tambalearse a finales del porfiriato. Salieron a la luz los conflictos agrarios que tuvieron una relación, más o menos tibia con el movimiento revolucionario.

Existe un elemento que no se puede olvidar: la dinámica de los pueblos seguía casi intacta en lo que respecta a su organización política y religiosa. Es decir, aquellas fuerzas políticas débiles que coexistían con los Cuatro Señoríos y que después formaron parte de un segundo tipo de gobierno autónomo continuaban de pie y al margen de las grandes estructuras hacendarias.

Buve $^{11}$ la nombró la élite pueblerina. Esta era tan importante que los gobiernos estatales del siglo XIX no tenían ninguna objeción en reconocerlas e incluirlas. El autor señaló que gobiernos como el de Próspero Cahuantzi (1885 a 1911) y el liberal de Miguel Lira y Ortega —dos veces gobernador del estado entre 1868 y 1877 - reconocían en este tipo de fuerza política uno de los pilares más importantes para la formación de los ayuntamientos. Tal fuerza llegó a ser tan importante que, según Cazarín ${ }^{12}$, gradualmente aumentó el número de cabeceras de ayuntamiento hasta llegar a 60.

Esto pone en evidencia la capacidad movilizadora, la legitimidad y tradición de la que gozaban y ejercían los pueblos que eran, en su nacimiento, una fuerza política débil, pero que poco a poco comenzó a gozar de un impulso político importante.

El respeto a las tradiciones y autoridades locales era conocido por las élites, y también por quienes llegaron a ser gobernadores o líderes políticos. Muchos de ellos provenían de esas comunidades.

En Tlaxcala se mantuvo la ideología de la comunidad-pueblo, según ${ }^{13}$ Buve, que permitió conservar la organización primigenia. La estructura de los pueblos tenía como base la familia extensa y las relaciones de compadrazgo. Ambos generaban lazos políticos y religiosos fuertes.

Bajo este clima surgió el conflicto revolucionario y la presencia del estado volvió a ser del mismo modo que en el proceso de independencia: tibia. Una vez culminado el movimiento armado, los gobernadores no tuvieron tintes agraristas. Se concentraron en el desarrollo industrial del estado.

Hacia el gobierno de Lázaro Cárdenas, en algunas zonas, el reparto agrario fue innegociable y en otras el ejido colectivo estaba siendo una realidad. Para 1950 había dos tipos de industrias en el estado: La primera compuesta por hilados y tejidos de algodón, de lana y artisela. La segunda por viejos y tradicionales tinacales que elaboraban pulque ${ }^{14}$.

\section{Los referentes indígenas siguen presentes}

Entre el proceso posindependentista y el revolucionario, aun cuando no estaba establecido, se seguían las prácticas políticas de antaño: el cacique como el que habla y representa la cosmovi-

\footnotetext{
${ }^{11}$ Buve, Raymond (1995), "Política y sociedad en Tlaxcala: unas interrogantes y unos hilos conductores a través de su historia, entre 1810 y 1910", en: El movimiento revolucionario en Tlaxcala, Universidad Iberoamericana Universidad Autónoma de Tlaxcala, México.

12 Cazarín Martínez, Angélica (2009), "Regiones y autonomía municipal en Tlaxcala” en: Scripta Ethnologica, vol. XXXI, Consejo Nacional de Investigaciones Científicas y Técnicas, Buenos Aires, pp. 59-89.

13 Buve, op. cit. nota 12.

14 RamíreZ, op. cit. nota 11, p. 192.
} 
sión indígena, y un representante del gobierno quien al principio era del gobierno novohispano, pero con el paso del tiempo con quien fuera su homologo.

El poder que poseía el cacique, debido a las negociaciones que debía emprender con los representantes del gobierno, se tornó en vínculos corporativos y oligárquicos. Ello derivó en la inclinación a ciertos grupos políticos y, poco a poco, la población fue cayendo en el abandono y olvido.

El cacicazgo funcionó como intermediario entre la comunidad y el gobierno por las lealtades generadas por los vínculos de parentesco o políticos. Ello mantuvo su base firme en la organización social local campesina, consecuencia de la participación agrícola aldeana, en los sistemas político-religiosos locales y en su interior se formaría su propia estructura de poder ${ }^{15}$.

El sistema socio-religioso que se resguardó llegó a incidir de manera significativa en los municipios, sobre todo en la elección del presidente municipal quien debía reunir una serie de servicios a la comunidad para que fuera apoyado en sus aspiraciones políticas. Nótese cómo las características de la persona quedaron por encima de cualquier ideología partidista.

Los procesos políticos y religiosos devenían de un vínculo familiar patrilineal. Esto se hizo evidente en las asambleas como instancias que permitían la participación de la comunidad tanto para la elección de sus representantes como para tratar asuntos de importancia común ${ }^{16}$.

Hacia los años setenta esta estructura político-religiosa tenía una fuerza considerable e influía en el funcionamiento de más de la mitad de los municipios. Era usual que las autoridades municipales no sólo se limitaran a atender lo suscrito en las leyes, sino que desempeñaban cargos relacionados con la organización religiosa y social del pueblo; incluso, de ello podía depender su arribo al ayuntamiento, dice Rendón ${ }^{17}$.

Una relación así no ha desaparecido, aunque se exprese de distintas maneras. La legitimidad del gobierno local y su vínculo con los cargos religiosos y civiles radica en que es resultado de un proceso comunitario que -aunque no es reconocido por las instituciones públicas- se erige sobre la tradición que constituye el trabajo por el bien común.

Nuevamente, volvemos a encontrar vestigios de un pasado pre y colonial. Las comunidades gozan y mantienen una estructura de gobierno que tienen raíces trascendentes que no se puede soslayar. El arraigo de la cultura indígena-pueblerina, como advierte Buve ${ }^{18}$, está vigente y forma parte de una historia de larga tradición en Tlaxcala. Sugiere que no es la capital ni los grandes centros urbanos sino la periferia. Ahí se articulan los verdaderos procesos políticos que no se han separado, no por indolencia ni ignorancia, de los religiosos. Son más bien vistos como un proceso totalizado y no fragmentado.

\section{La evolución jurídica de los Usos y Costumbres en Tlaxcala}

\subsection{El Sistema de Cargos como raíz de los Usos y Costumbres}

En la mayor parte de las comunidades latinoamericanas que gozan de raíces prehispánicas se puede notar la práctica de los Usos y Costumbres. Estos tienen su antecedente más cercano en

\footnotetext{
${ }^{15}$ Buve, op. cit. nota 12, p. 121.

${ }^{16}$ RENDón, op. cit. nota 10.

17 Ídem.

${ }^{18}$ Buve, op. cit. nota 12. 
el sistema de cargos que son, según $\operatorname{Korsbaek}^{19}$, oficios religiosos ocupados con base en una rotación entre los hombres de una comunidad.

[...] el resultado de una mezcla de formas prehispánicas de organización política, que sobrevivieron a la conquista, y el ayuntamiento español impuesto a los indígenas durante la Colonia. De tal arreglo nació un nuevo patrón de organización que incluye una ordenación jerárquica de las posiciones de autoridad; donde un individuo tiene que cubrir un número de posiciones previas antes de poder alcanzar las posiciones más altas dentro de la jerarquía ${ }^{20}$.

El período suele ser de un año. Esto quiere decir que, durante un período relativamente corto, generalmente los varones se hacen responsables de obligaciones asociadas al cargo. Cuando este concluye, lo mismo ocurre con derechos, privilegios y la autoridad asociada a este.

Los sistemas de cargo se caracterizan porque los hombres varones adultos de la comunidad dan su tiempo y energía sin pago alguno para servir en diversos cargos y no se espera que la misma persona continúe asumiéndolos en los años subsiguientes porque debe ser tomado por otro varón. Lo que se busca es que todos ellos participen de forma rotativa.

El cargo toma, dependiendo de la tarea, la mitad o totalidad del tiempo de trabajo de una persona. Por eso tienen ese nombre: literalmente son una carga que permite que la familia pierda tiempo de trabajo y abandone ventajas económicas para cumplir con las obligaciones del oficio. Es importante señalar que, aunque el cargo lo toma una persona, la familia se involucra y forma parte importante en la realización de las tareas.

Aunque los sistemas de cargo se encuentran de forma más frecuente en las comunidades indígenas, no se puede dejar de lado su existencia en comunidades mestizas que pueden ser urbanas o semi-urbanas. Portal ${ }^{21}$ señala que la diferencia que ocurre con estos y los Sistemas de Cargo indígenas - en los que se estructura con cuatro o más niveles jerárquicos - es que se encuentran solo dos tipos de cargos: fiscales y mayordomos, así como un desprendimiento de lo político. Es decir, se hace una clara división entre el espacio público y el privado.

Las restricciones y requisitos para ocupar el cargo se rigen por ciertos criterios. En el caso indígena es necesario escalar la estructura piramidal — símbolo de adquisición de experiencia y sabiduría - hasta llegar a tener el de mayor jerarquía. Para entonces será un anciano sapiente. A una persona le lleva toda una vida servir para alcanzar el mayor prestigio. Cabe destacar que no se disocia lo político. Hay una vinculación extraordinaria entre religión y política que se da de manera casi natural.

En el caso mestizo, urbano o semi-urbano - usualmente no conservan la estructura piramidal- los cargos, generalmente, pueden ser adquiridos sin requisitos previos y no se ocupan de manera sucesiva. El prestigio no se relaciona con la edad y a esta no se le atribuye la sabiduría. Basta que cumpla con sus tareas porque no tiene gran injerencia con las decisiones políticas.

\footnotetext{
${ }^{19}$ Korsbaek, Lief (1996), Introducción al Sistema de Cargos, Universidad Autónoma del Estado de México, México.

${ }^{20}$ Durand Ponte, Víctor Manuel (2007), Prólogo, en: J. Hernández-Díaz, Ciudadanías diferenciadas en un estado multicultural: los usos y costumbres en Oaxaca, Siglo XXI/Universidad Autónoma Benito Juárez de Oaxaca, México, pp. 39-40.

${ }^{21}$ Portal, Ana Maria (1996), "Características generales del Sistema de Cargo de mayordomía urbana”, Revista Iztapalapa, enero-junio, Universidad Autónoma Metropolitana_Iztapalapa, México.
} 
Asimismo, la participación no se hace buscando prestigio ante la comunidad. Su labor se asocia más al arraigo personal de sus creencias religiosas.

Los cargos implican llevar un minucioso registro de quiénes cooperan y con cuánto, cuestión que se hace del conocimiento público durante la ceremonia del cambio de poderes. De esta manera se convierten en una serie de vigías de las pertenecías de la comunidad. Con ello se define y se decide quién pertenece al pueblo y quién no. Se trata de un mecanismo de inclusión y exclusión. A través de esta estructura social de participación se garantiza una normatividad que se refrenda anualmente y por otro lado una participación continua de un número muy amplio de pobladores.

El Sistema garantiza y legitima un proceso de transmisión de saberes y prácticas tradicionales que van de generación en generación en la toma de decisiones y en la trasparencia de los procesos políticos y religiosos.

En los casos urbano y semi-urbano los Sistema de Cargo se han desmembrado de los Usos y Costumbres para convertirse en dos instituciones distintas. Por su parte, estos se pueden leer a partir de las mismas premisas que la primera institución. Deben entenderse como el reconocimiento grupal de una forma de proceder, de decir o de pensar que perdura a lo largo del tiempo $\mathrm{y}$ se inscribe en un determinado contexto.

La característica de los usos y costumbres es que al desprenderse de su institución originaria - Sistemas de Cargo - se rigen bajo un asunto puramente político el cual determina a aquel que será el encargado de escuchar a la comunidad y, en conjunto, tomar decisiones.

Esta manera de proceder se inserta en la discusión sobre si se hace patente la fusión total o el relativismo cultural. En la primera perspectiva cualquier comunidad -indígena, mestiza, urbana o semi-urbana- debe regirse bajo los mismos códigos que el resto del país. Con ello se pierde toda costumbre que regía la vida de una localidad. Desde la segunda perspectiva el Estado respeta las formas en que una comunidad, bajo la costumbre que ha migrado de generación en generación, tiene y obedece no por la fuerza de la ley.

En una serie de lenguas indígenas, como en la zapoteco de Yaganiza, los usos y costumbres que continúan la cultura ancestral de la comunidad - se traduce como sistema de lo parejo. Así se corrobora que este método de elección tiene como premisa que el más sabio de la comunidad tome en sus manos a la comunidad.

Eso significa que el filtro para ser votado será muy riguroso porque requiere madurez y sabiduría provista por los años. No solo se debe pertenecer a la comunidad y ser un adulto sino haber demostrado, con los cargos anteriores, que se ha madurado y se es capaz de tomar decisiones adecuadas para todos.

Sin embargo, aquí se hace visible un problema porque este régimen también supone la sujeción a otras costumbres cuya legitimidad presenta duda. Por ejemplo, en algunas comunidades, sólo los varones pueden ser votados, no así las mujeres. El derecho al voto se adquiere antes de la mayoría de edad cuando se es un varón casado, las madres solteras son representadas por sus padres, las personas avecindadas tienen voz, pero no voto.

Por otra parte, este tipo de sistema ha permitido a la comunidad, defender sus tierras y la propiedad comunal, así como evitar ser encuadrados, por fuerza o despotismo, en algún partido político (De la Garza, 2009). Así se explica que estos sigan vigentes y sean objeto de protección normativa y de defensa. 


\subsection{Los Usos y Costumbres: una práctica ancestral en Tlaxcala}

Aunque no estaba establecido en el papel, en la práctica, las representaciones determinadas bajo el sistema de usos y costumbres se remontan a antes del Virreinato y, luego, bajo una mixtura entre lo español e indígena, misma que fue tomando forma hasta llegar al plano institucional.

En 1985 los regidores podían ser electos bajo la forma de usos y costumbres. Es decir, señala Armenta $^{22}$, se introduce en Tlaxcala algo que se puede llamar el principio de representación comunal y territorial dentro del ayuntamiento. Los regidores ya no son nombrados por esta institución sino por la comunidad e integrados como regidores del pueblo. Bajo este tenor, el ayuntamiento se compone de tres tipos de regidores: los regidores de mayoría relativa, los de representación proporcional y los de pueblo.

Diez años después, en 1995, se introdujo la figura de Presidente de Comunidad. Este pertenecía al ayuntamiento como regidor del pueblo, pero con atribuciones y recursos municipales legislados por el Congreso local, mismos que son ejercidos en su ámbito micro local.

La Constitución Política del Estado Libre y Soberano de Tlaxcala en su artículo 87 fracción $I V$ inciso b, reconoce dos sistemas de elección de presidentes de Comunidad en el Estado: por el principio de sufragio universal, libre, directo y secreto y mediante la modalidad de usos $y$ costumbres. Con el reconocimiento al sistema de usos y costumbres como un método de elección, el Estado respeta las formas de organización política y social propias de las comunidades que practican este método concediéndoles a los presidentes de Comunidad electos bajo este sistema, las mismas atribuciones que a los electos por el principio de sufragio universal ${ }^{23}$.

Hacia 2006, el Instituto Electoral de Tlaxcala contabilizaba 98 comunidades que elegían bajo esta figura a los Presidentes de Comunidad.

Las presidencias de comunidad funcionan en esta entidad como órganos desconcentrados de la administración pública municipal y se eligen cada tres años, en la misma fecha de la elección del ayuntamiento, con la asistencia técnica, jurídica y logística del Instituto Electoral de Tlaxcala (en el que no hay representación indígena) ${ }^{24}$.

Ante las reformas, en materia electoral, las comunidades que ejercen su derecho de elección por Usos y Costumbres no estaban obligadas a dar cuenta del método bajo el cual elegían y el Instituto Electoral de Tlaxcala no estaba facultado para intervenir en ellas. Sin embargo, la legislación electoral vigente y las reformas al artículo 116 de la Ley Municipal del Estado de Tlaxcala, facultan y obligan a dicho Instituto a tener presencia en las asambleas y dar la asistencia técnica, jurídica y logística que se requiera. Tales reformas se instituyeron el 15 de mayo de 2009.

Artículo 116. Las presidencias de comunidad son órganos desconcentrados de la administración pública municipal, estarán a cargo de un Presidente de Comunidad, el cual será electo cada tres años conforme a lo previsto en la Constitución Política del Estado Libre y Soberano

\footnotetext{
22 Armenta Ramírez, Petra (2006), Elecciones por usos y costumbres en México, Revista Letras Jurídicas, volumen 14, julio-diciembre, Xalapa, CEDEGS, [en línea], disponible en: http://letrasjuridicas.com.mx/Volumenes/14/armenta14.pdf.

${ }^{23}$ Íbidem, p. 6.

${ }^{24}$ Singer Sochet, Martha (2014), "Avances y pendientes de la representación política indígena en México", Programa de Acompañamiento Ciudadano (PAC), Democracia intercultural, Instituto Nacional Electoral (INE), [en línea], disponible en: http://pac.ife.org.mx/democracia_intercultural/docs/Articulo_Singer.pdf.
} 
de Tlaxcala, el Código de Instituciones y Procedimientos Electorales para el Estado y las bases siguientes:

I. La elección de presidentes de comunidad se realizará en la misma fecha en que se celebre la elección de Ayuntamientos. El Consejo General del Instituto Electoral de Tlaxcala, determinará qué presidencias de comunidad se elegirán mediante el sistema de usos y costumbres, de acuerdo al catálogo que para tal efecto expida.

VI. Los presidentes de comunidad electos de acuerdo a usos y costumbres de la comunidad que los elija, se acreditarán ante el Ayuntamiento que corresponda mediante el acta de la asamblea de la población, a la que invariablemente deberá Asistir un representante del Instituto Electoral del Estado; éste comunicará al Ayuntamiento, los resultados obtenidos en la elección correspondiente ${ }^{25}$.

Actualmente, señala Orta ${ }^{26}$, Tlaxcala cuenta con 393 comunidades distribuidas en los 60 municipios del estado, y de estas, en 94 se elige presidente de comunidad por usos y costumbres. Dichas comunidades corresponden a un total de 24 municipios. En las 299 comunidades restantes, los representantes populares son electos por mayoría relativa, es decir, con voto directo en urnas.

En las comunidades en las que se ejerce el voto por usos y costumbres los métodos de elección son muy variados: a mano alzada, voto secreto, o bien anotando el nombre del candidato en pizarras y registrando en ellas los votos que va adquiriendo. Hay casos en los que se anota quién vota por cada candidato. Son medios regulatorios no del voto sino de la participación de quienes integran la comunidad. Es una medida que permite que la comunidad califique a los próximos candidatos; es decir, involucra la forma y los argumentos para votar a favor o en contra y la manera de conducirse con los demás miembros de la comunidad. Aún cuando no se esté de acuerdo con ellos estos medios regulatorios permiten ver la calidad moral de una persona. Eso, ancestralmente, ha sido muy importante porque representa el grado de responsabilidad que se tiene con la comunidad.

Una nueva reforma se hizo en Tlaxcala. El 1 de enero de 2017 entró en vigor, y como resultado de las votaciones de los integrantes de la LXI Legislatura: se ignoró lo establecido en la Constitución Política de los Estados Unidos Mexicanos en su artículo 40 debido a que

los presidentes de comunidad carecen de legitimidad para representar en el cabildo mediante el voto, a los habitantes de todo el municipio, ya que solamente fueron elegidos por una comunidad y no por el total de la población municipal". Así, la redacción del artículo 120 del reglamento municipal se determina a "acudir a las sesiones de cabildo sólo con voz.

El problema es que esto implicaba una especie de involución de todo lo ganado en materia electoral, así como el reconocimiento a una cosmovisión de los hechos políticos. Algunas voces se han alzado para señalar que se trata de una violación a los derechos por dos razones: la primera, porque las presidencias de comunidad están reconocidas como un orden más de

\footnotetext{
${ }^{25}$ H. Congreso del Estado Libre y Soberano del Estado de Tlaxcala, Ley Municipal del Estado de Tlaxcala, Secretaría Parlamentaria, Periódico oficial del Gobierno del Estado, 12 de mayo de 2011, [en línea], disponible en: http://www.capitaltlaxcala.gob.mx/wp-content/uploads/2014/o2/ley_municipal_del_estado_de_tlaxcala.pdf

${ }^{26}$ OrTA, Gerardo (2015), “Actualizo ITE reglamento de elecciones por usos y costumbres”, en: Periódico digital gentlx, Tlaxcala, 20 de noviembre, [en línea], disponible en: http://gentetlx.com.mx/2015/11/2o/actualizo-ite-reglamento-de-elecciones-por-usos-y-costumbres/ [consultado el 21 de noviembre de 2017].
} 
gobierno; la segunda porque la ley establece que a todos los integrantes del ayuntamiento se les reconoce el carácter de munícipes sin restricción alguna. De ahí que es inviable que algunos tengan voto y otros no. Por otro lado, minaba lo ya establecido tanto en la Constitución Federal como en lo establecido en algunos Pactos Internacionales.

El argumento bajo el que se decretó fue que los presidentes auxiliares exigían partidas presupuestales fuera de toda lógica, así como un alto nivel de corrupción al interior de las gestiones comunitarias.

Se discutió en febrero de 2017 sobre la posibilidad de reformar y devolver el voto a los presidentes de comunidad con la consigna de deliberar ampliamente sobre los asuntos del presupuesto, pero no de la corrupción.

Se ve, entonces, que la forma en que los Usos y Costumbres devenidos de una figura más amplia - el sistema de cargos - ha caminado laberintos muy problemáticos que han implicado el reconocimiento, jurídico, de costumbres ancestrales que están interiorizadas en las comunidades y que no permiten la fragmentación de las personas sino una comunión que se ejerce ante cualquier conflicto y que se resuelve en la comunidad y desde ella.

\subsection{Los Usos y Costumbres bajo la lupa constitucional}

Las formas cómo se han venido dictando las políticas de los Estados han caído en una fragmentación desmedida: el ser humano es uno en la vida pública y otro en la privada. Esto no es así.

En un contexto democrático, una de las funciones más importantes de la representación política es condensar y expresar la voluntad del pueblo. Es a través de ella, que los distintos intereses e identidades presentes en la sociedad, forman parte de los procesos decisorios que se llevan a cabo en su nombre; por ello, la representación política debe ser incluyente, heterogénea y plural $^{27}$.

Es por ello que no debe ser única la condición de celebrar las elecciones, conforme a los que se establezca en los distintos órganos constitucionales, y los representantes decidan sobre los asuntos que competen a una comunidad o a un conjunto de ellas para que la democracia sea efectiva.

Se goza de una brecha amplia entre gobernados y gobernantes. Los primeros desconfían a cabalidad de los segundos porque no saben cómo, su representante, se ha conducido en su comunidad, quién es su familia, cómo desarrolló los cargos que ha tenido, etc. Es decir, no se sabe - como se veía en líneas anteriores - bajo qué calidad moral se rigen. En tanto, los gobernantes al estar tan desvinculados de las comunidades ven sus responsabilidades como trámites administrativos y no visualizan cómo se trastoca la vida comunitaria y personal con sus decisiones. Nótese una distancia importante entre ambos actores. De ahí que ha sido necesario abrir, institucionalmente, una vía más amplia.

Del sistema de partido hegemónico se ha transitado hacia un sistema de partidos plural y, a pesar de que con frecuencia los procesos electorales siguen suscitando profundas controversias, también se ha pasado de elecciones sin competencia a elecciones cada vez más competidas, con lo que ha ganado plu-

\footnotetext{
27 Singer, op. cit. nota 25, p. 1.
} 
ralidad la representación política. Sin embargo, aún se advierten limitaciones para la participación del conjunto de la ciudadanía en la toma de decisiones ${ }^{28}$.

Lo mismo ha ocurrido en relación con las candidaturas independientes y con la constante permanencia de los pueblos indígenas.

No cabe duda que la visión liberal racionalista, así como el predominio de una visión individualista, basada en la autonomía personal, hizo que el camino fuera más complejo cuando se trataba de fraguar instituciones que mediaran entre el Estado y aquellas sociedades que integran en su ser cultural lo que denominamos "usos y costumbre" y que en nuestro país son caracterizadas bajo el calificativo de indígenas ${ }^{29}$.

Sin embargo, bajo el fundamento, dice $\operatorname{Armenta}^{30}$, de que en México se reconoce que la soberanía reside esencial y originariamente en el pueblo - mismo que en todo tiempo, tiene el inalienable derecho de alterar o modificar su forma de gobierno- cada órgano del poder público de los distintos ámbitos competenciales válidamente pueda legislar, sobre una misma materia que este reservada a los estados, pero con la sabida obligación constitucional de respetar la supremacía constitucional y los demás principios que se prevén por los tratados internacionales que estén de acuerdo con la Constitución Federal y que pasen por el tamiz procedimental respectivo (art. 76, fracción 1;89, fracción X, y 133 de la Constitución Federal.

Así, se encuentra que en el sistema jurídico mexicano que los documentos y normas jurídicas fundamentales relativas a los Usos y Costumbres se encuentran referidos en:

La Constitución Federal: artículos 1 y 2, apartado A

El Convenio número 169 sobre Pueblos Indígenas y Tribales en Países Independientes

Pacto Internacional de Derechos Civiles y Políticos: artículo 1, 2, 3, 25, y 27

Pacto Internacional de Derechos Económicos, Sociales y Culturales: artículo 1, 2, 4, y 5

La Convención Americana sobre Derechos Humanos: artículos 1, 2, 8, parágrafo 1,23, 25, 29 y 30

Cabe resaltar que la democracia electoral por usos y costumbres debe ser entendida a partir del principio de justicia y equidad. La lucha, señala Armenta31 por el reconocimiento de los pueblos indígenas - sabiendo que en todo momento han estado presentes - ha sido una pieza clave en el Convenio 169 de la OIT, fechado en junio de 1989. Este dicta que reconociendo las aspiraciones de esos pueblos a asumir el control de sus propias instituciones y formas de vida y de

\footnotetext{
${ }^{28}$ Íbidem, p. 2.

${ }^{29}$ Cienfuegos Salgado, David (2013), Justiciabilidad Electoral en México Reflexiones, Retrospectivas y Retos, Tribunal Electoral del Estado de Veracruz de Ignacio de la Llave, México, p. 3. [en línea], disponible en: https://biblio. juridicas.unam.mx/bjv/detalle-libro/3268-justiciabilidad-electoral-en-mexico-reflexiones-retrospectivas-y-retos.

${ }^{30}$ Armenta, op. cit. nota 23.

${ }^{31}$ Íbidem.
}

CienCIA JURÍDICA. Departamento de Derecho. División de Derecho, Política y Gobierno, Universidad de Guanajuato - Año 7, No. 13, 2018 
su desarrollo económico y a mantener y fortalecer sus identidades, lenguas y religiones, dentro del marco de los Estados en que viven ${ }^{32}$.

Lo anterior halla justificación en la medida en la que de estos pueblos emana parte de la cultura que hoy involucra a indígenas y mestizos. Sin embargo, se encuentra una prerrogativa. Estos grupos deben gozar de la conciencia de su identidad indígena o tribal deberá considerarse un criterio fundamental para determinar los grupos a los que se aplican las disposiciones del presente Convenio ${ }^{33}$.

Así, era necesario que para 1992, se reconociera constitucionalmente, que México es una nación pluricultural -existen alrededor de 65 comunidades indígenas diseminados por todo el país-que la ley debe proteger para promover el desarrollo de su cultura. De esta forma se estaba aceptando que México no es un país homogéneo sino heterogéneo, que el ideal de la Revolución Mexicana se había cumplido. En efecto, se es mexicano, pero no necesariamente se está adscrito a una única cultura ni mucho menos a un único ideal de nación. Este es un México en el que las miradas culturales de los diversos pueblos indígenas difieren, en gran medida, de los ideales occidentales.

En 1996, refiere Cienfuegos ${ }^{34}$, con la inclusión de la justicia electoral en el ámbito del Poder Judicial de la Federación, se reconoció un nuevo tipo de mecanismos que permitiría la defensa de los derechos políticos de los pueblos indígenas. Para 2001 se agregó que, dado lo anterior, era necesario conservar sus instituciones políticas, culturales y económicas.

Así se estableció que pueden

elegir, en los municipios con población indígena, representantes ante los ayuntamientos [y] las constituciones y leyes de las entidades federativas reconocerán y regularán estos derechos en los municipios, con el propósito de fortalecer la participación y representación política de conformidad con sus tradiciones y normas internas ${ }^{35}$.

Se entiende, entonces, que los pueblos y comunidades indígenas en las entidades federativas elegirán, de acuerdo con sus principios, normas, procedimientos y prácticas tradicionales, a las autoridades o representantes para el ejercicio de sus formas propias de gobierno interno, garantizando la participación de hombres y mujeres en condiciones de igualdad, guardando las normas establecidas en la Constitución, las constituciones locales y las leyes aplicables, según Leyva (2015). Sin embargo, solo 11 estados han establecido procedimientos para que lo demandado se haga realidad.

\footnotetext{
32 Comisión Nacional para el Desarrollo de los Pueblos Indígenas, (1989), Convenio 169 de la OIT sobre Pueblos Indígenas y Tribales en Países Independientes, México, p. 4.

33 Íbidem. p. 5.

34 Cienfuegos, op. cit. nota 30.

${ }^{35}$ Legislación Congreso de la Unión, Secretaría General de Servicios Parlamentarios (2017), Constitución Política de los Estados Unidos Mexicanos, Secretaría de Gobernación, Diario Oficial de la Federación, 15, 09, 2017, artículo 2, apartadlo A, inciso VII, [en línea], disponía en: http://www.diputados.gob.mx/LeyesBiblio/ pdf/1_150917.pdf.
} 


\section{Conclusiones}

Los privilegios otorgados a Tlaxcala, como resultado de la alianza indígena-española, fueron continuamente amenazados en relación con perder su autonomía territorial y su categoría como provincia que les permitía mantener una relación mucho más directa con la corona española.

Esta condición les otorgó una forma de gobierno propia que, aunque incluyó características europeas, mantuvo la esencia de las relaciones comunitarias entre los pueblos, mismas que representaron un bastión importante de poder local moral, religioso y político.

Desde la fundación de Tlaxcala como provincia española hubo necesidad de incorporar a las élites de los pueblos originarios, que después serían municipios rurales. Esa necesidad de inclusión provino, por un lado, de la insistencia de atender a los privilegios ganados, pero sobre todo por el evidente control legítimo, moral, social y político-religioso que estas autoridades ejercían en sus pueblos cuya incidencia llegaba a la organización política municipal.

La legitimidad ganada a través del trabajo en beneficio de la comunidad y el barrio, de base familiar patrilineal, continúa siendo reconocida como parte de las exigencias para integrar el gobierno local. Si bien esto continúa como parte de la vida religiosa, en términos de la organización política intervienen los partidos políticos y los intereses de familiares y de grupo.

La estructura de poder - que se ha basado en las relaciones de parentesco, compadrazgo y clientelismo - son propias de la sociedad rural que prevaleció durante el siglo XIX y XX, aunque siguen siendo las familias de abolengo y aquellos grupos cercanos a ellas en los que sigue recayendo el poder.

Buve $^{36}$ considera que existen una serie de acontecimientos de tipo político, económico y social presentes a lo largo de la historia del estado. Se trata de una serie de pautas y actitudes que se originaron en la época colonial, o incluso antes, y que se mantuvieron presentes a lo largo del siglo XIX, particularmente entre los años 1810 y 1910 . Estas son:

La geopolítica del estado

La dinámica de las élites económicas y políticas tlaxcaltecas que incluyen sus facciones al interior

La relación con Puebla

La dinámica de los pueblos indios que, en lo posterior, se convertirían en municipios rurales que incluye las relaciones que mantenían con gobernantes y la élite económica

Así, se considera que existe una línea de continuidad que puede ser trazada a partir de la organización política local. En cierta manera, se defiende que las autoridades auxiliares, hoy instituidas y reglamentadas a partir de la Ley Orgánica Municipal, son el resultado de una serie de acontecimientos que tuvieron inicio con la alianza indígenas-españoles. Al no asumirse como pueblos conquistados, los tlaxcaltecas buscaron el respeto y la continuidad de sus formas políticas de organización. La respuesta fue la instauración del único cabildo indio novohispano que tuvo su remanente en los pueblos.

A partir de entonces fueron reconocidos por el poder moral y formal que representaba tanto en términos religiosos como en los civiles y políticos. La organización política de los pueblos

\footnotetext{
${ }^{36}$ Buve, op. cit. nota 12. 
se mantuvo con sus propios liderazgos, con sus propias reglas e intereses en los que ahora se incluye al sistema de partidos y no al revés.

La cuestión no cambiará con la inserción de los Usos y Costumbres en la Constitución. Ello porque, aunque se reglamentó, era parte de la práctica cotidiana. El reconocimiento, habría que decir, es vital porque al estar institucionalizado se reconoce no solo la historicidad que contiene y que ha configurado a todo un estado, sino que permitirá que se valore de una forma diferente todo un legado político no occidental que tiene como base la común unión de las personas.

Cabe mencionar que los usos y costumbres no son contradictorios con las formas democráticas. Pueden mirarse desde una democracia en la que es vital no sólo la participación a nivel electoral sino una participación efectiva y fáctica dentro que permita a cada miembro saber quién los representa y al representante tener muy claro cuáles son las demandas, pero sobre todo cuáles son las que mejor convienen a la comunidad.

\section{Fuentes de información}

\section{Bibliografía}

Armenta Ramírez, Petra (2006), Elecciones por usos y costumbres en México, Revista Letras Jurídicas, volumen 14, julio-diciembre, Xalapa, CEDEGS, [en línea], disponible en: http://letrasjuridicas.com.mx/Volumenes/14/armenta14.pdf

Bustamante López, Carlos (2013), El quebrantamiento de los privilegios, autonomía, guerra y constitución gaditana en Tlaxcala, 1780-1824, México, Universidad Autónoma de Tlaxcala, Benemérita Universidad Autónoma de Puebla, Educación y cultura, asesoría y promoción, S.C.

Buve, Raymond (1995), "Política y sociedad en Tlaxcala: unas interrogantes y unos hilos conductores a través de su historia, entre 1810 y 1910", en: El movimiento revolucionario en Tlaxcala, Universidad Iberoamericana Universidad Autónoma de Tlaxcala, México.

Cazarín Martínez, Angélica (2009), “Regiones y autonomía municipal en Tlaxcala” en: Scripta Ethnologica, vol. XXXI, Consejo Nacional de Investigaciones Científicas y Técnicas, Buenos Aires.

Cienfuegos Salgado, David (2013), Justiciabilidad Electoral en México Reflexiones, Retrospectivas y Retos, Tribunal Electoral del Estado de Veracruz de Ignacio de la Llave, México, [en línea], disponible en: https://biblio.juridicas.unam.mx/bjv/detalle-libro/3268justiciabilidad-electoral-en-mexico-reflexiones-retrospectivas-y-retos.

De la Garza Talavera, Rafael (2009), Usos y costumbres y participación política en México, Tribunal Electoral del Poder Judicial de la Federación, México.

Durand Ponte, Víctor Manuel (2007), Prólogo, en: J. Hernández-Díaz, Ciudadanías diferenciadas en un estado multicultural: los usos y costumbres en Oaxaca, Siglo XXI/Universidad Autónoma Benito Juárez de Oaxaca, México.

García CAlCLIni, Nestor (1989), Culturas hibridas,. Estrategias para entrar y salir de la modernidad, México, Grijalbo. 
Gibson, Charles (1991), Tlaxcala en el Siglo XVI, Fondo de Cultura Económica, México.

Korsbaek, Lief (1996), Introducción al Sistema de Cargos, Universidad Autónoma del Estado de México, México.

Martínez Barcacs, Andrea y Sempat Assadourian, Carlos (1991), Tlaxcala una historia compartida siglo XVI, Volumen IX, México, Consejo Nacional para la Cultura y las Artes, Gobierno del estado de Tlaxcala.

Muñoz Camargo, Diego (2013), Historia de Tlaxcala, Universidad, Autónoma de Tlaxcala y Centro de Investigaciones y Estudios Superiores en Antropología Social, México.

Portal, Ana Maria (1996), “Características generales del Sistema de Cargo de mayordomía urbana”, Revista Iztapalapa, enero-junio, Universidad Autónoma Metropolitana_ Iztapalapa, México.

Ramírez Rancancio, Mario (1990), El sistema de haciendas en Tlaxcala, Consejo Nacional para la Cultura y las Artes, México.

Ramos Galicia, Yolanda, Sánchez, Jaime y Díaz de la Mora, Armando (2016), Los Colonizadores Tlaxcaltecas, siglos XVI al XIX, México, Archivo Histórico del Estado de Tlaxcala y Gobierno del Estado de Tlaxcala.

Rendón Garcini, Ricardo (1996), Breve historia de Tlaxcala, México, Fideicomiso Historia de las Américas, El Colegio de México y Fondo de Cultura Económica.

Singer Sochet, Martha (2014), "Avances y pendientes de la representación política indígena en México", Programa de Acompañamiento Ciudadano (PAC), Democracia intercultural, Instituto Nacional Electoral (INE), [en línea], disponible en: http://pac.ife.org.mx/democracia_intercultural/docs/Articulo_Singer.pdf.

\section{Hemerográficas}

LeYva, Ivonne (2015), "Usos y Costumbres”, en Periódico digital gentlx, Tlaxcala, 17 de noviembre, [en línea], disponible en: http://gentetlx.com.mx/2015/11/17/usos-y-costumbres-2/ [consultado el 21 de noviembre de 2017].

OrTA, Gerardo (2015), “Actualizo ITE reglamento de elecciones por usos y costumbres", en: Periódico digital gentlx, Tlaxcala, 20 de noviembre, [en línea], disponible en: http://gentetlx.com.mx/2015/11/2o/actualizo-ite-reglamento-de-elecciones-por-usos-y-costumbres/ [consultado el 21 de noviembre de 2017].

Legislación Congreso de la Unión, Secretaría General de Servicios ParlamentaRIOs (2017), Constitución Política de los Estados Unidos Mexicanos, Secretaría de Gobernación, Diario Oficial de la Federación, 15, 09, 2017, [en línea], disponía en: http://www. diputados.gob.mx/LeyesBiblio/pdf/__150917.pdf.

H. Congreso del Estado Libre y Soberano del Estado de Tlaxcala, Ley Municipal del Estado de Tlaxcala, Secretaría Parlamentaria, Periódico oficial del Gobierno del Esta- 
do, 12 de mayo de 2011, [en línea], disponible en: $h t t p: / / w w w . c a p i t a l t l a x c a l a . g o b . m x / w p$ content/uploads/2014/o2/ley_municipal_del_estado_de_tlaxcala.pdf.

Comisión Nacional para el Desarrollo de los Pueblos Indígenas, (1989), Convenio 169 de la OIT sobre Pueblos Indígenas y Tribales en Países Independientes, México. 